\title{
Thermoregulation in spinal cord injury: the challenge of the Atlanta Paralympics
}

\author{
B Cairbre McCann \\ Portland Maine, USA. Editorial Board Member of Spinal Cord
}

Keywords: spinal cord injury; wheelchair sports; thermal stress; thermal regulation; Atlanta paralympics

\section{Introduction}

From August 14th-20th 1996, following the regular Olympic Games, Atlanta Georgia will be the host city for the Xth Paralympic games, continuing a tradition begun in Rome 1960. Then, for the first time, athletes with spinal cord injury (SCI), competed in an Olympic sports event in the same site as the 'regular' Olympics, creating the sports title 'Paralympics'. Since 1967 the Paralympics have grown to include other disability groups, notably amputees, cerebral palsy, and blind athletes. In Atlanta there will be 4000 competitors representing 110 countries, who will compete in a wide range of sports, including track and road racing, field events, swimming, weightlifting and wheelchair basketball.

Thermoregulation in sports is a particular concern whenever climate extremes are encountered in competition. ${ }^{1}$ Put in its simplest terms, hyperthermia is the potential problem when the body's rate of heat production is greater than its ability to dissipate this heat. ${ }^{2}$ Even experienced athletes are subject to severe heat related illness. ${ }^{3}$ The conditions in Atlanta will be severe and will require particular recognition and accommodation by participants. For this reason the Atlanta Paralympic Organising Committee (APOC) have issued special guidelines for competitors, officials and spectators, to assist in dealing with such conditions. ${ }^{4}$ In the case of competitors with SCI, many of whom already are required to deal with compromised thermoregulation, the potential hazard is more evident and deserves review.

\section{The changing role of sports in spinal cord injury: a historical perspective}

The participation of SCI athletes in an international Olympic level sports event illustrates how competitive sport has changed our understanding of the physical capacity of persons with SCI. It is through sports that persons with SCI have revealed their ultimate physical work capacities. This capacity has been possible only through intensive muscular and cardiovascular training by wheelchair exercise. It is at this level of performance that thermoregulation assumes such importance. Prior to 1976, in track events, paraplegic athletes were restricted by regulation to the 100 yards dash, while those who were tetraplegic as well as women athletes were limited to 60 yards. It was not until 1976 that the mile race was considered safe for paraplegic athletes. In Atlanta, all levels of SCI will compete in track events of up to 5000 metres, and in the marathon. The inclusion of wheelchair track athletes in exhibition events at the 1984 regular Olympics represented perhaps their ultimate recognition as athletes.

The earliest use of sports in SCI management was as a tool in physical rehabilitation. ${ }^{5}$ The Stoke Mandeville Spinal Centre was the site of the earliest sports activity of this type. It was only later that competitive sports emerged as a specific valued experience, outside the medical environment. This is where it exists today. It should be noted that sports activities for SCI athletes encompasses more than these two examples, rehabilitation sport and elite sport. In between there is a range of recreational sports for pleasure and fitness. This is the level at which the majority of those active in wheelchair sports engage, both for physical and psychological benefits. The sports scientific basis for competetive wheelchair sports was established through many studies, mostly using wheelchair ergometry or modified bicycle arm ergometry. ${ }^{6,7}$ These studies have revealed the potential for high levels of physical work in individuals with SCI. Human performance studies of this kind were parallelled by an everadvancing level of athletic performances in track events, roadracing and in swimming. It is in this context of high level sport that SCI athletes, together with other athletes with disabilities are competing in Atlanta.

\section{Exercise and thermal stress}

\section{Underlying physiological mechanisms}

In the normal physiological state, the body core temperature remains almost exactly constant $\left(37^{\circ} \mathrm{C}\right.$, $98^{\circ} \mathrm{F}$ ) when an individual is exposed to a wide range of 
ambient temperatures. This occurs through a delicately balanced control system, which is regulated primarily through the hypothalamus. The hypothalamus 'thermostat' responds to changes in the core temperature greater than $1{ }^{\circ} \mathrm{C}$ from the set point of $37^{\circ} \mathrm{C}\left(98^{\circ} \mathrm{F}\right)$. Peripheral skin thermal receptors provide further input to the central control center. In response to an increase in body core temperature, adjustments in arteriolar skin flow and sweat gland activity allow loss of body heat by radiation, conduction, convection or evaporation. ${ }^{8}$ This response is influenced by the ambient temperature conditions, and also by the athlete's level of athletic fitness and the physiological integrity of the sweating and cardiovascluar mechanisms. Vigorous muscular activity on the other hand may be sufficient to elevate body core temperature to $40^{\circ} \mathrm{C}\left(100^{\circ} \mathrm{F}\right)$ in as little as $5 \mathrm{~min}$, during which the metabolic rate increases to $20-25$ times above the basal level. ${ }^{9}$ In conditions of muscular work in extreme heat, sweating is critical for effective evaporative heat loss. Hydration then assumes a prominent role and its importance has been extensively emphasised. ${ }^{10}$

Thermoregulation of athletes with spinal injury

Non athletes with SCI have long been recognised as experiencing difficulties in regulating body temperature. $^{11,12}$ This is due to the loss of autonomic nervous system control of skin blood flow and sweating below the level of injury. Guttmann and colleagues performed a landmark study on thermoregulation in spinal man in 1958, using a heat chamber to create the requisite heat conditions. ${ }^{13}$ These and subsequent studies involved nonexercising subjects. In contrast to the extensive scientific literature available on heat stress and injury in the non-disabled worker or athlete, there has been little study of physiological responses or adaptations of athletes with SCI in response to such stress. ${ }^{14,15}$

\section{Manifestations of heat stress}

Heat illness can be manifested by a series of disabling complications. In order of increasing severity they comprise heat cramps, heat exhaustion and heat stroke. ${ }^{9}$ Symptoms of these conditions often overlap. Heat cramps, or involuntary muscle spasms, represent an early manifestation, usually observed in the muscles exercised, and are likely to be due to an imbalance in the body electrolytes. Heat exhaustion is most likely due to ineffective circulatory adjustments compounded by depletion of extracellular fluid. It is usually characterised by a weak rapid pulse, low blood pressure, headache, dizziness and general weakness. The temperature may be $38-40^{\circ} \mathrm{C}\left(100.4-104^{\circ} \mathrm{F}\right)$. Heat stroke represents a failure of thermoregulation resulting in dangerously high body temperatures $\left(41^{\circ} \mathrm{C} / 106^{\circ} \mathrm{F}\right)$ or higher and is a medical emergency. Sweating has usually ceased at this level of circulatory failure.

\section{Environment temperature measurement and use of the heat stress index}

When high temperature is associated with high humidity, as is expected in Atlanta (so called wet heat) the measurement of air temperature alone is only a partial expression of the total extent of environmental heat stress. It becomes necessary to also take into account humidity, ambient radiation, and the convective effect of air currents. In Atlanta climate conditions evaporative heat loss represents the main mechanism for temperature control. High humidity seriously limits this mechanism, which in turn is dependent on sweating to be effective. Neither will air temperature (dry bulb) reading capture the direct radiated heat from sun on a cloudless day or the indirect radiation from hot pavement or surrounding buildings as is likely during the marathon. Recognising the need to measure all of these factors which contribute to environmental heat stress, a measure called the heat stress index temperature was developed, and has most recently been described by Sparling. ${ }^{16}$ In brief, a composite heat stress index is derived from combining measurements of ambient temperature (dry bulb), relative humidity (wet bulb) and solar radiant heat (black globe temperature). A summary of how this index is used to characterise heat stress is reproduced in Table 1. The availability of this information on a day to day basis serves to increase awareness and alert all participants to the risks on any particular day and at any particular time of the day. It also offers the competition officials the option to change an event schedule or even cancel competition in the process of extreme or hazardous conditions.

\section{Atlanta climate in August}

Climatic conditions in Atlanta have been recorded since 1879. From this information it can be expected that the average daily high temperature in August will be about $31^{\circ} \mathrm{C}\left(88^{\circ} \mathrm{F}\right)$ and that the average low will be $21^{\circ} \mathrm{C}\left(70^{\circ} \mathrm{F}\right) .{ }^{16}$ The highest temperature recorded during this period was $40.6^{\circ} \mathrm{C}\left(105^{\circ} \mathrm{F}\right)$ in 1980 . The average early-morning relative humidity is $89-90 \%$ at $07.00 \mathrm{~h}$, lowering to $61 \%$ by $13.00 \mathrm{~h}$. The precipitation pattern is variable in August, with an average of $8.5 \mathrm{cms}$ ( 3.3 inches). It is characteristic that humidity is highest in the morning, but the increase in radiation temperature over the course of a clear day without clouds may make for a higher heat stress index

Table 1 Composite heat stress index

\begin{tabular}{lcc}
\hline F Range & C Range & Risk level \\
Below 64 & Below 18 & Low \\
$64-73$ & 1823 & Moderate \\
$73-82$ & $23-28$ & High \\
Above 82 & Above 28 & Extreme \\
Above 90 & Above 32 & Cancel event? \\
\hline
\end{tabular}


temperature in the evening than in the morning. This is of great importance in choosing the schedules for the marathon and longer distance races for either the morning or the evening. Daily gathering and posting of the heat stress index temperature will therefore be of the utmost importance for athletes, medical and coaching staffs, and organisers, as they anticipate their competition schedules.

\section{Guidelines for preventing severe heat injury}

\section{Advance preparation}

Adequate preparation should help avert such extreme effects as heat exhaustion or heat stroke in the presence of the extreme 'wet heat' conditions in Atlanta. Advance knowledge of the climatic conditions and availability of guidelines to help in coping with them will be most helpful. ${ }^{4}$ The Atlanta Paralympic Organising Committee have circulated these guidelines to teams from the participating nations. Daily posting of the temperature conditions expected for the day's events will serve as a further alert to athletes, medical staffs, team managers and coaches. It should not be forgotten that officials on the field and spectators will also be exposed to these conditions, and will need to take equal precautions.

\section{Acclimatisation}

Maximum acclimatization to exercise in extreme heat is achieved in about 2 weeks, but benefits have been reported within 1 week. To achieve maximum benefit however, requires a very high level of fitness and training. Hard training even in cooler weather results in physiological adaptations including increased blood plasma volume, increased sweat rate, decreased electrolyte loss with sweat, initiation of sweating at lower body temperatures and decreased perception of thermal stress. ${ }^{18,19}$ It has been suggested that athletes who are unable to experience the true Atlanta conditions prior to actual competition, attempt to train in simulated hot humid environments such as a warm humid room or space such as a natatorium.

Recognition of heat stress signs and symptoms

Since there is considerable variability in individual heat tolerance, team managers should be aware of particular heat sensitivity among team members, and be very watchful for early symptoms of heat stress. It is important that athletes be educated about symptoms of heat stress. While performance in competition will undoubtedly be effected adversely in extreme heat conditions, effects greater than anticipated might represent a degree of hypohydration. Race officials in the longer-distance races should be alert to warning signs of impending collapse. Such signs might include clumsiness, erratic wheelchair propulsion, complaints of headache, nausea or dizziness, apathy and any evidence of confusion by other changes in mental status.
Shade, wind and clothing

When outdoors it is advisable to seek shady and breezy areas. Outdoor competition areas will have adjacent tented or shaded facilities. There will also be ready access to drinking water, as well as water for wetting exposed body surface areas. This method of increasing evaporative heat loss is of particular value to those SCI athletes with higher levels of sweating loss. Exercise clothing should be of light colour, loose, made of breathable material, allowing maximum skin exposure. The increasing desire of wheelchair track athletes to wear skin contact track suit pants impedes evaporative efficiency and should probably be avoided in Atlanta conditions.

\section{Hydration}

Adequate hydration is a fundamental component of thermoregulation in such heat conditions. ${ }^{10.19}$ Dehydration inhibits sweating volume, which is so necessary for evaporative heat loss. It also impedes cardiovascular efficiency by lessening the plasma volume available for conducting heat to the body surface. Availability of water is not sufficient. There is a need for athletes and team staff to maintain adequate intake by means of fluid intake monitoring. Daily weighing is a most practical way to keep track of hydration status. A systematic schedule of fluid intake before, during and after training and events should be maintained.

\section{Medical support and organisation}

Medical support and organisation in preparation for the Atlanta Paralympics has been ongoing. These preparations will ensure the provision of shade protection and ready access to water. The sports medicine support will also include a response capability to provide any immediate resuscitation services which may be necessary. There will also be available ambulance and hospital services backup if required.

\section{References}

1 American College of Sports Medicine. Position stand on prevention of thermal injuries during distance running. Med Sci Sports Exerc 1987; 19: 529-533.

2 Adolph EI. Physiology of man in the desert. New York; Interservice 1947; pp 5-43.

3 Lee R, Bishop GF, Ashton CM. Severe heat stroke in an experienced athlete. Med J Aust 1990; 153: 100-104.

4 Atlanta Paralympic Organising Committee. Sports Dept. 1996 Atlanta Paralympic Games. Guidelines for hydration in hot and humid environments. 1996

5 Guttmann L. Sport. In: Spinal Cord Injuries. Comprehensive Management and Research 2nd Edn. Blackwell Scientific Publications: Oxford 1976 pp $305-313$.

6 Dreisinger TE, Londeree BR. Wheelchair Exercise: A Review. Paraplegia 1982; 20: 20-34.

7 Wicks HR, Oldridge NB, Cameron BJ, Jones NL. Arm cranking and wheelchair ergometry in elite spinal cord-injured athletes Med Sci Sport Exerc 1983; 15: 224-231. 
8 Astrand P-O, Rodahl K. Temperature Regulation. In: Textbook of work Physiology. Physiological Basis of Exercise. McGraw Hill Book Co 3rd Edn. 1986, pp 583-600.

9 McArdle WD, Katch FI, Katch VL. Exercise and Thermal Stress In: Exercise Physiology 2nd Edn. Lea and Febiger: Philadelphia 1985 pp $441-466$.

10 Sawka MN, Francesconi RP, Young AJ, Pandolph KB. Influence of hydration level and body fluids on exercise performance in the heat. JAMA 1984; 252: $1165-1169$.

11 Pollock LJ et al. Defects in regulatory mechanisms of autonomic function in injuries to the spinal cord. J Neurophys 1951; 14: $85-$ 94.

12 Totel GL. Physiological responses of heat of resting man with impaired sweat capacity. J App Physiol 1974; 37: 346-352.

13 Guttmann L, Silver J, Wyndham $\mathrm{CH}$. Thermoregulation in Spinal Man. J Physiol 1958; 142: $406-419$.

14 Dawson B, Bridle J, Lockwood RJ. Thermoregulation of paraplegic and able bodied men during prolonged exercise in hot and cool climates. Paraplegia 1994; 32: $860-870$.
15 Armstrong LE, Maresh CM. Thermoregulation of athletes with spinal cord injury. In: The Outlook. Vista 93. Steadward, Nelson, Wheeler, Eds., Rick Hansen Centre, Edmonton 1994. Canada.

16 Sparling PB. Expected Environmental Conditions for the 1996 Summer Olympic Games in Atlanta. Editorial. Clin J Sports Med 1995; 5: $220-222$.

17 Cohen JS, Gisolfi CV. Effects of interval training on work-heat tolerance of young women. Med Sci Sports Exerc 1982; 14: 4652.

18 Armstrong LE, Pandolph KB. Physical training, cardiorespiratory physical fitness and exercise-heat tolerance. In: Pandolph KB, Sawka MN, Gonzales RR. (eds) Human Performance Physiology and Environmental Medicine at Terrestrial Extremes. Benchmark Press, Inc, Indianapolis 1988.

19 Gisolfi CV, Duckman SM. Guidelines for optimum replacement beverages for different athletic events. Med Sci Sports Exerc 1992; 24: $679-687$ 